Am J Ophthalmol. 2018 March ; 187: xx-xxvii. doi:10.1016/j.ajo.2017.11.021.

\title{
Endophthalmitis: Then and Now
}

Nidhi Relhan, MD, Richard K. Forster, MD, and Harry W. Flynn Jr., MD

Department of Ophthalmology, Bascom Palmer Eye Institute, University of Miami Miller School of Medicine, Miami, Florida, USA

\section{Abstract}

Purpose-To report historically evolving strategies (then and now) in prevention and management of endophthalmitis.

Design-A perspective on relevant topics in the prophylaxis and management of endophthalmitis.

Methodology-This is an author selected review of studies leading to changes in strategies for endophthalmitis management over the last 100 years.

Results-The current perspective discusses the trends and strategies over the past century. Historically, three endophthalmitis time-periods have existed and include the pre-antimicrobial era, the predominantly systemic antimicrobial era, and the current intravitreal antimicrobial era. The management of endophthalmitis from different etiologies including endogenous, postinjection, post-cataract surgery and other anterior segment related (e.g. post-penetrating keratoplasty), bleb-associated, glaucoma drainage device-associated, and open globe injuryassociated are discussed. Specific etiologies may predict most common microbial causes and may guide differing management strategies. Pars plana vitrectomy offers theoretical advantages but is generally reserved for patients with more advanced disease.

Conclusions-Inspite of advances over the past 100 years, endophthalmitis is an important sight threatening complication. Timely management with the appropriate use of antimicrobial agents may optimize visual outcomes.

Endophthalmitis prophylaxis and treatment have evolved tremendously over time. During the pre-antimicrobial era (1918 to 1941), reported treatments included administration of anti-serum, application of mercury oxycyanide, aqueous mercurochrome drops, local heat, typhoid vaccine intravenously in increasing doses on alternate days, or intramuscular injection of boiled milk or $\mathrm{x}$-ray therapy to a conjunctival bleb. ${ }^{1,2}$ In a meta-analysis between 1920 and 1940, the reported rate of post-cataract surgery endophthalmitis was $2 \%$ (approximately $1.17 \%$ in 1940 's and approximately $0.30 \%$ in 1950 's). ${ }^{3}$ In the subsequent

Corresponding Author/Address for reprints: Harry W Flynn Jr. MD., Department of Ophthalmology, Bascom Palmer Eye Institute, University of Miami, Miller School of Medicine, 900 N.W. 17th Street, Miami, Florida 33136, USA, Phone Number +1-305-326-6118, Fax - 305-326-6417, hflynn@ med.miami.edu.

Disclosure: None for authors.

Publisher's Disclaimer: This is a PDF file of an unedited manuscript that has been accepted for publication. As a service to our customers we are providing this early version of the manuscript. The manuscript will undergo copyediting, typesetting, and review of the resulting proof before it is published in its final citable form. Please note that during the production process errors may be discovered which could affect the content, and all legal disclaimers that apply to the journal pertain. 
antimicrobial era (mid 1940's to early 1970's), systemic and local application of antimicrobials were increasingly utilized, and better treatment outcomes were achieved. In a retrospective series by Allen et al in 1964, the reported rate of endophthalmitis was $0.11 \%$ (22/20,000 cataract extractions) and a significant risk for postoperative infection was "failure to prescribe topical antibiotics preoperatively". ${ }^{4}$ In 1974, Allen and Mangiaracine reported a lower rate of infection $0.086 \%$ (31/36,000 cataract extractions). ${ }^{5}$ They attributed the lower rates of infection to (1) meticulous aseptic technique, (2) minimally traumatic surgery, and (3) preoperative antibiotic prophylaxis using a combination of chloramphenicol-polymyxin B sulfate drops and erythromycin ointment.

During the intravitreal antimicrobial era (early 1970's to the present time), experimental studies laid the foundation for intravitreal injection of antimicrobials, the most important component of endophthalmitis management today. During this era, 1970s, Peyman et al developed an oscillatory vitrectomy system and conducted experimental studies on rabbits undergoing vitrectomy or lensectomy. On the day following rabbit surgery, all 12 of the animals developed endophthalmitis in his study. Peyman recognized that systemic antibiotics would provide minimal potential for successful treatment and he began investigations of intravitreally injected antimicrobials and determined nontoxic doses (Personal communication Dr. Gholam Peyman, Nov 11, 2017). Peyman and collaborators provided invaluable historical experiments that ultimately led to the modern strategy of intravitreal antibiotics to treat most patients with endophthalmitis. 6,7

In 1974, Forster reported 33 cases of endophthalmitis for whom diagnostic vitrectomy was performed and 2 patients also received intraocular antibiotics. ${ }^{8}$ Further, advent of small gauge pars plana vitrectomy may have contributed to better outcomes (anatomic and functional). In the past, hospital based treatment was utilized but today, endophthalmitis is usually treated in outpatient setting. Silicone oil is a useful adjunct in retarding bacterial growth and repairing complex cases of endophthalmitis with retinal detachment. ${ }^{9}$

In today's world, post-cataract surgery and post-intravitreal injection are the leading causes of endophthalmitis. Specific etiologies may predict different microbial causes and may require different management strategies. The purpose of this perspective is to describe the evolution of approaches for the prevention and treatment of endophthalmitis. In addition, this perspective provides updated clinical information on the incidence, most common microbial causes, treatment outcomes and resistant microorganisms.

\section{Endogenous Endophthalmitis}

Endophthalmitis caused by hematogenous spread of infectious organisms (fungal/bacteria) is an uncommon entity, most frequently reported in systemically ill or immunocompromised patients. ${ }^{10}$ Incidence rates are reported to be $0.04 \%-0.4 \%$ with associated risk factors including intravenous drug use, diabetes mellitus, immune compromise, malignancy, prolonged hospital stay or intravenous antibiotic administration.

Metastatic endophthalmitis was one of the earliest reported endophthalmitis cases in the 1918 issue of the American Journal Ophthalmology ${ }^{1}$ in which Haden reported metastatic 
endophthalmitis in a severely ill patient with meningococcal cerebro-spinal meningitis who was managed with intravenous anti-meningococcal serum. The now predictable outcome was failure and phthisis bulbi. In 1946, Lewis and Wallace reported another case of endogenous endophthalmitis in a 14-month-old girl who was managed by administration of 10,000 Oxford units of penicillin every 3 hours, sodium salicylate along with atropine sulphate ointment for a period of 6 to 7 days. ${ }^{11}$ The infection resolved but visual outcome could not be ascertained as the patient was a child.

In a more contemporary series, Holland et al in 1982 first reported some of the ocular pathologies in patients of acquired immunodeficiency syndrome (AIDS) including cottonwool spots, cytomegalovirus retinitis, severe retinal periphlebitis, and conjunctival Kaposi's sarcoma. ${ }^{12}$ Later in 1989, Davis et al reported endogenous bacterial endophthalmitis in patients with AIDS. ${ }^{13}$

In recent years, metastatic (or endogenous) endophthalmitis has become more common with intravenous drug use (IVDU). ${ }^{10}$ Increasing opioid use in the United States has led to a rise in reported intravenous drug use-associated endogenous endophthalmitis. ${ }^{14}$ Modjtahedi et al in 2017 reported a retrospective case series of 32 eyes (30 patients) with IVDU-associated endophthalmitis, among which causative organisms were identified in 24/32 eyes (59\% fungal and $16 \%$ bacterial). ${ }^{15}$ This series highlights the possible bacterial as well as the more common fungal causes for endogenous endophthalmitis. Management generally includes obtaining vitreous fluid for diagnostic evaluation and treatment with both intravitreal and systemic antimicrobial therapy. If blood cultures have already identified an organism, vitreous sampling may not be necessary.

\section{Endophthalmitis occurring Post-Intravitreal Injection}

Clinical trials showing beneficial effects of anti-vascular endothelial growth factor (VEGF) agents in 2005 and the number of intravitreal injections performed yearly have increased exponentially now becoming the most common procedure performed in ophthalmology.

Retrospective reviews and population based studies have reported the incidence of endophthalmitis following intravitreal injection ranging from $0.016 \%$ to $0.053 \% .{ }^{16}$ The rates are higher after intravitreal corticosteroids than after intravitreal anti-VEGF agents. In one report, 159,066 intravitreal injection procedures were performed during 2006 to $2016 .{ }^{17,18}$ The reported overall endophthalmitis incidence rate after intravitreal injection procedure was $0.014 \%,(23 / 159,066)$. It is important to note that in this study, the incidence of endophthalmitis following three different intravitreal anti-VEGF agents were similar (bevacizumab 10/79,105 [0.013\%], ranibizumab 6/36,791 [0.016\%] and aflibercept 7/42,478 $[0.016 \%]) .{ }^{19}$ This indicates that the rate of incidence of endophthalmitis is not affected by the type of intravitreal anti-VEGF drug. Endophthalmitis following intravitreal anti-VEGF agents caused by Streptococcus species has been reported to have the worst visual acuity outcomes. The American Academy of Ophthalmology (AAO) Preferred Practice Pattern guidelines for the intravitreal injections have evolved over the past 10 years. In some worldwide geographic areas, the procedure is performed in the operating rooms, with all 
sterile precautions and prophylactic topical antibiotics use (pre- and post-injection). In other areas, the procedure is performed in the outpatient clinic with no topical antibiotics.

Based on a review of published literature and expert panel deliberations, Avery et al (2014) published updated guidelines for the intravitreal injection prophylaxis. ${ }^{20}$ The panel emphasized the need for preoperative preparation of eyelid margins and conjunctiva with povidone-iodine, avoiding needle touch with eyelid as well as lack of evidence to support the routine use of prophylactic pre-, peri-, and post-injection antibiotics. In one study of outcomes at a tertiary referral center, topical antibiotics were not used before, during, or after intravitreal injections after 2008. ${ }^{19}$ The rates of post-injection endophthalmitis during the time-period 2015 to 2016 when no topical antibiotics were used (approximately 1 in 20,000 injections) were lower compared to the time period 2006 to 2007 when topical antibiotics were utilized (approximately 1 in 4,000 injections). ${ }^{19}$ This lower rate of endophthalmitis after intravitreal anti-VEGF injection is confirmed by the American Academy of Ophthalmology (AAO) IRIS (Intelligent Research In-Sight) Registry of 2,600,000 injections, where the reported rates of endophthalmitis within 15 days among age related macular degeneration patients treated with aflibercept, bevacizumab, and ranibizumab was $0.0059 \%(1 / 17,000), 0.0071 \%(1 / 14,000)$, and $0.0052 \%(1 / 19,000)$ respectively (Personal communication David Parke II, October 2017). This implies that topical antibiotics are not essential for the intravitreal injection procedure.

\section{Endophthalmitis occurring Post-Cataract Surgery}

In 1949, Givner reported a case of acute-onset post-cataract surgery endophthalmitis caused by Neisseria catarrhalis managed by irrigating the anterior chamber with penicillin $(2,000$ units per cc) followed by placing penicillin soaked cotton pads in the conjunctival sac for 30 -minutes along with systemic penicillin and sulfadiazine for a period of one week. ${ }^{21}$ The post treatment visual acuity recovered to 20/20.

Potential risk factors associated with the development of postoperative endophthalmitis include preoperative, intraoperative, and postoperative features (Table 1). With advent of newer surgical equipment, instruments, technologies, and evolution from intracapsular cataract excision to extracapsular cataract excision to small incision cataract surgery to phacoemulsification, cataract surgery has greatly improved with reduced surgical time and better outcomes. In the $21^{\text {st }}$ century, the incidence of post-cataract endophthalmitis is reported to be between $0.012 \%$ and $1.3 \% .^{22}$

Between 1991 and 1994, a randomized clinical trial, the Endophthalmitis Vitrectomy Study (EVS) provided high-level evidence for treatment of endophthalmitis associated with cataract surgery or secondary intraocular lens (IOL) surgery. ${ }^{23}$ The EVS provided guidelines regarding the use of intravitreal antibiotics with pars plana vitrectomy (PPV) or vitreous tap (TAP). The EVS reported that in a subgroup of patients with presenting visual acuity of hand motions or better, there was no difference in the visual outcome (immediate PPV or TAP). ${ }^{23}$ However, in the subgroup of patients with presenting visual acuity of light perception only, visual outcomes were better with immediate PPV compared to TAP. The EVS findings may not be generalizable to endophthalmitis associated with other conditions The routine use of 
adjunctive intravitreous corticosteroids for treatment of acute-onset postoperative endophthalmitis is controversial due to the possibility of deleterious effects and insufficient evidence supporting efficacy. ${ }^{24}$ For endophthalmitis occurring after cataract surgery, management with intravitreal antimicrobial injections has greatly contributed to achieving better outcomes (anatomic and functional). Also, most treatment of endophthalmitis is now in an outpatient setting.

Yannuzzi et al (2017) reviewed the clinical features, causative organisms, and visual acuity (VA) outcomes associated with culture-positive acute-onset endophthalmitis after clear corneal cataract surgery between 2006 and 2015 at a tertiary referral center. ${ }^{25}$ Causative organisms were coagulase-negative Staphylococcus (39/63, 62\%), Staphylococcus aureus $(7 / 63,11 \%)$, and Streptococcus species $(7 / 63,11 \%)$. Visual acuity $220 / 40$ was achieved in 24 of $63(38 \%)$ eyes but pre-existing comorbidities in these patients were not excluded. ${ }^{25}$

In the pursuit of zero endophthalmitis, cataract surgeons have utilized various measures of endophthalmitis prophylaxis (preoperative/intraoperative/postoperative). Preoperative eyelid and conjunctiva antisepsis with povidone-iodine, use of filtered antibiotics in irrigating solution (vancomycin and gentamycin in Gills solution), ${ }^{26}$ topical antibiotics (pre- and postoperatively) and injection of subconjunctival or intracameral antibiotics at the conclusion of surgery have been utilized. Topical antibiotics are widespread and entrenched in the United States with higher postoperative use compared to preoperative use. Retrospective studies and surrogate evidence suggest efficacy of topical antibiotics, however the efficacy remains unproven in a placebo-controlled prospective study. Povidone-iodine antisepsis is the only technique to reach category II evidence in reducing endophthalmitis rates. ${ }^{27}$

The use of intracameral antibiotics at the time of cataract surgery (cephalosporins) was reported in a randomized clinical trial (RCT) in 2007 conducted by the European Society of Cataract \& Refractive Surgeons (ESCRS). ${ }^{28}$ Today, vancomycin, cefuroxime, and moxifloxacin are the three most commonly used intracameral antibiotics during cataract surgery. Various criticisms of intracameral antibiotics include the potential risk of dilutional error, contamination, cost-benefit concerns, number needed to treat, antibiotic stewardship and potential complications (infection, toxic anterior segment syndrome (TASS) and hemorrhagic occlusive retinal vasculitis - HORV). The non-availability of pharmaceutical preparation of cefuroxime and published reports on fluoroquinolone resistance among coagulase-negative Staphylococci are also important issues. ${ }^{29}$ Despite these concerns over intracameral antibiotics, $47 \%$ of ASCRS members routinely use or plan to use intracameral prophylactic antibiotics for cataract surgery. ${ }^{30}$ Both now and in future, big data will continue to provide outcome measures and trends for endophthalmitis prevention and treatment. ${ }^{31}$

\section{Chronic Endophthalmitis}

Chronic postoperative endophthalmitis is defined as endophthalmitis occurring more than 6 weeks after cataract surgery. Chronic endophthalmitis is associated with less virulent organisms introduced at the time of intraocular procedure. ${ }^{32}$ The infection may progress slowly to become clinically apparent months or years after the procedure. In these cases, the microorganisms are usually sequestered in the capsular bag where they are partially 
sheltered from the immune system. Propionibacterium acnes and fungi are the most common microorganisms associated with chronic/delayed-onset endophthalmitis. ${ }^{33}$ Treatment may involve removal of the capsular bag along with IOL explantation in addition to pars plana vitrectomy and injection of intravitreal antibiotics.

Delayed-onset postoperative endophthalmitis may result from an acquired weakness in the ocular surface allowing late entry of organisms. Examples of delayed-onset endophthalmitis include infection through glaucoma filtering blebs, corneal sutures, fistulas from previous trauma and clear corneal wound leak.

\section{Endophthalmitis occurring Post-Glaucoma Surgery}

Exposed glaucoma drainage implants, leaking or infected blebs or microinvasive glaucoma surgery (MIGS) may lead to endophthalmitis, months or years following surgery. In one study, the reported five-year cumulative incidence was $0.45 \%-1.7 \% .{ }^{34}$ Younger age, use of antimetabolites during surgery, inferior blebs, thin avascular blebs, blebitis and chronic antibiotic use are reported predisposing risk factors. Coagulase-negative Staphylococci, Streptococcus species and Staphylococcus species have been commonly reported to be the causative organisms. ${ }^{35}$ The management includes bleb revision and subconjunctival antibiotics in addition to vitreous tap/pars plana vitrectomy and/or intravitreal antibiotics injection. Song et al (2001) reported 49 eyes with delayed-onset bleb-associated endophthalmitis at a University Referral Center (Bascom Palmer Eye Institute during 1996 to 2001). ${ }^{36}$ Removal of the exposed tube/implant/device may become necessary, but, when the tube is not exposed then it may be initially retained. ${ }^{35}$ The visual outcomes are generally poor in these cases because of pre-existing reduced vision from glaucoma and involvement with more virulent organisms. ${ }^{35,} 36$

\section{Endophthalmitis associated with Open Globe Injury}

Endophthalmitis rates following open globe injuries has been reported to be as high as 15 to $30 \% .{ }^{37}$ In patients with post-traumatic endophthalmitis, pars plana vitrectomy with injection of intravitreal antibiotics are usually required. Systemic antibiotics in endophthalmitis associated with open globe injury are generally utilized.

Presence of retained IOFB is an important risk factor for the development of endophthalmitis. Removal of IOFB is not always possible at the time of primary globe closure and can be delayed until the availability of expert vitreoretinal services. Retained organic intraocular foreign body should be removed as early as possible. Inert or nonorganic foreign body (metallic or glass) can be removed later when infection and inflammation decrease, and the media become clear enough to allow safe removal of the foreign body. Banker et al reported no increase in rates of endophthalmitis or poorer visual outcomes in patients where IOFB removal was delayed up to 36 hours. ${ }^{37}$

Widely practiced prophylactic use of intravitreal and systemic antibiotics may decrease the rate of posttraumatic endophthalmitis in eyes with open globe injury. In large series of patients with open globe injuries, early wound closure and use of systemic levofloxacin was associated with a very low endophthalmitis risk. ${ }^{38}$ In patients presenting with open globe 
injury, systemic antibiotics are usually considered as a prophylaxis for endophthalmitis (intravenous vancomycin plus ceftazidime or oral levofloxacin prior to surgery). Prophylactic intravitreal antibiotics may be considered depending upon the zone of open globe injury: less often in Zone 1 open globe injuries, but more often considered in Zone 2 or Zone 3 open globe injuries. ${ }^{39}$

\section{Emerging Antimicrobial Resistance}

Today emerging resistance to commonly used antimicrobial agents is a great challenge in health care. Increasing antimicrobial resistance may arise from: 1) widespread agricultural use of antibiotics 2) the overuse of antibiotics in hospitals and outpatient clinics, and 3) intrinsic genetic factors. The majority of total antibiotic consumption in the United States involves uninfected animals raised for food (approximately 80\%) and 62\% of these antibiotics are the drugs also used to treat human diseases. ${ }^{40,41}$ The Centers for Disease Control and Prevention (2013) reported that infections due to antibiotic-resistant bacteria affect 2 million people in the United States every year, incurring \$20 billion in direct health care costs and $\$ 35$ billion in lost productivity. ${ }^{42}$ Every year more than 20,000 deaths in the United States and Europe are reported to be due to infections caused by antimicrobialresistant organisms. ${ }^{43}$ The issue of increasing antimicrobial resistance is a challenging problem and emphasizes the urgent need for antibiotic stewardship.

\section{Current Intravitreal Antimicrobials for Endophthalmitis}

Intravitreal antimicrobials are generally used in the treatment of all categories of endophthalmitis. Intravitreal antibiotics currently used in the management of the endophthalmitis include vancomycin $(1.0 \mathrm{mg} / 0.1 \mathrm{cc})$ and ceftazidime $(2.25 \mathrm{mg} / 0.1 \mathrm{cc})$ or amikacin $(0.4 \mathrm{mg} / 0.1 \mathrm{cc})$ for bacterial endophthalmitis. Intravitreal antifungal agents include amphotericin-B $(0.005 \mathrm{mg} / 0.1 \mathrm{cc})$ or voriconazole $(0.1 \mathrm{mg} / 0.2 \mathrm{cc})$. Current antimicrobial agents may not provide adequate coverage for emerging resistant isolates causing endophthalmitis. Reduced vancomycin susceptibility or vancomycin resistance is an important concern today and for the future. Gram-positive organisms were reported to be $100 \%$ susceptible to vancomycin as reported by the Endophthalmitis Vitrectomy Study (EVS) and the Antibiotic Resistance Monitoring in Ocular micRorganisms (ARMOR) 2009 surveillance study. However, a PubMed review (1990-2015) reported 27 cases of endophthalmitis caused by gram-positive organisms with reduced vancomycin susceptibility or vancomycin resistance. ${ }^{44}$ Yannuzzi et al (2017) reported a number of isolates which were resistant to cephalosporins and fluoroquinolones. ${ }^{25}$ Stringham et al (2017) reported a trend of fluoroquinolone non-susceptibility among coagulase-negative Staphylococcus isolates causing endophthalmitis (1995 - 2016) at a University Referral Center. ${ }^{29}$ Although the study was entirely a laboratory in vitro evaluation of microbial susceptibilities, the implications of this report are important to clinicians using fluoroquinolones before, during or after ophthalmic surgery. In the EVS, $89.5 \%$ of gram-negative organisms causing endophthalmitis were susceptible to both amikacin and ceftazidime. The antibiotic susceptibility pattern of gram-negative bacteria from vitreous isolates has not significantly changed in the United States. ${ }^{45}$ However, from other parts of the world, reduced antimicrobial susceptibility of gram-negative organisms to amikacin as well as ceftazidime has been reported. ${ }^{46,47}$ Dave et 
al (2016) reported that among 139 cases of endophthalmitis caused by gram-negative organisms, 56 were resistant to ceftazidime and among those 11 cases were treated with intravitreal imipenem $(50 \mu \mathrm{g} / 0.1 \mathrm{~mL}) .{ }^{46}$ Endophthalmitis caused by antibiotic-resistant organisms generally have poor visual outcomes. ${ }^{44,46}$

Alternative antimicrobial agents have been utilized in cases of resistant organisms (grampositive organisms/gram-negative organisms/fungal organisms). ${ }^{48}$ In these studies, no single antibiotic provided complete coverage against all microorganisms. In another study, vitrectomy using $0.025 \%$ povidone-iodine in the infusion fluid was performed in 4 eyes with endophthalmitis. Resolution of endophthalmitis occurred in all cases with improvement in visual acuity and no reported complications. Use of povidone-iodine in irrigating fluid or as an intravitreal injection is a viable prophylactic and therapeutic future option.

\section{Antibiotic Stewardship}

Antibiotic stewardship programs to optimize antibiotic selection and reduce the inappropriate use of broad-spectrum antibiotics are recommended by the Centers for Disease Control and Prevention (CDC) to address the emerging antimicrobial resistance. The CDC called for new medication management standards (MM.09.01.01) for hospitals, critical access hospitals, and nursing care centers (available at https://www.jointcommission.org/ assets/1/6/New_Antimicrobial_Stewardship_Standard.pdf effective January 1, 2017). The strategic measures include tracking clinical data on antibiotic-resistant infections, causes of infections, root cause analysis and antibiotic stewardship programs as mandated by the Centers for Medicare and Medicaid Services (CMS) in 2017.49

\section{Endophthalmitis Management - Where are we "Now"}

Preoperative povidone-iodine antisepsis, intravitreal antimicrobial injections, improved vitrectomy instrumentation, availability of silicone oil as adjunctive treatment and newer alternative antimicrobials contribute to better outcome for patients with endophthalmitis. Further advances in the microbiology diagnosis including polymerase chain reaction (PCR) and newer molecular application of peptide nucleic acid-fluorescence in situ hybridization (PNA-FISH) are promising diagnostic tools but their clinical usefulness remains uncertain at present. ${ }^{50} \mathrm{Big}$ data now allows us to better evaluate outcomes and to compare rates of endophthalmitis (IRIS Registry).

\section{Conclusions}

Over the past 100 years, approaches to endophthalmitis have greatly changed (Table 2). The current management includes collecting vitreous samples, performing TAP or PPV, and injection of intravitreal antimicrobials in most cases. Systemic and topical antimicrobials, intravitreal steroids and silicone oil are useful adjunctive therapies. Even in today's world, the management of endophthalmitis can be challenging, and visual outcomes may be poor. 


\section{Acknowledgments}

Funding Support - Supported in part by the National Institute of Health (NIH) Center Core Grant P30EY014801 (Bethesda, Maryland) and Research to Prevent Blindness Unrestricted Grant (New York, New York) to the Department of Ophthalmology, Bascom Palmer Eye Institute, Miami, Florida, USA.

\section{References}

1. Haden HC. Metastatic Endophthalmitis Associated by Epidemic Cerebro-Spinal Meninigitis. American Journal of Ophthalmology. 1918; 1:647-650.

2. Sugar HS, Zekman T. Late infection of filtering conjunctival scars. Am J Ophthalmol. 1958; 46:155-170. [PubMed: 13559349]

3. Leopold IH. Doyne memorial lecture: Management of intraocular infection. Trans Ophthalmol Soc UK. 1971; 91:577-610. [PubMed: 4336297]

4. Allen HF, Mangiaracine AB. Bacterial Endophthalmitis Afetr Cataract Extraction. A Study Of 22 Infections In 20,000 Operations. Arch Ophthalmol. 1964; 72:454-462. [PubMed: 14191094]

5. Allen HF, Mangiaracine AB. Bacterial endophthalmitis after cataract extraction. II. Incidence in 36,000 consecutive operations with special reference to preoperative topical antibiotics. Arch Ophthalmol. 1974; 91:3-7. [PubMed: 4357788]

6. Daily MJ, Peyman GA, Fishman G. Intravitreal injection of methicillin for treatment of endophthalmitis. Am J Ophthalmol. 1973; 76:343-350. [PubMed: 4542289]

7. Axelrod AJ, Peyman GA, Apple DJ. Toxicity of intravitreal injection of amphotericin B. Am J Ophthalmol. 1973; 76:578-583. [PubMed: 4743811]

8. Forster RK. Endophthalmitis. Diagnostic cultures and visual results. Arch Ophthalmol. 1974; 92:387-392. [PubMed: 4547957]

9. Dave VP, Pathengay A, Relhan N, et al. Endophthalmitis and Concurrent or Delayed-Onset Rhegmatogenous Retinal Detachment Managed With Pars Plana Vitrectomy, Intravitreal Antibiotics, and Silicone Oil. Ophthalmic Surg Lasers Imaging Retina. 2017; 48:546-551. [PubMed: 28728182]

10. Relhan N, Schwartz SG, Flynn HW Jr. Endogenous Fungal Endophthalmitis: An Increasing Problem Among Intravenous Drug Users. JAMA. 2017; 318:741-742. [PubMed: 28829854]

11. Lewis PM, Wallace GM. Metastatic endophthalmitis. Am J Ophthalmol. 1947; 30:332.

12. Holland GN, Gottlieb MS, Yee RD, Schanker HM, Pettit TH. Ocular disorders associated with a new severe acquired cellular immunodeficiency syndrome. Am J Ophthalmol. 1982; 93:393-402. [PubMed: 6280503]

13. Davis JL, Nussenblatt RB, Bachman DM, Chan CC, Palestine AG. Endogenous bacterial retinitis in AIDS. Am J Ophthalmol. 1989; 107:613-623. [PubMed: 2658616]

14. Tirpack AR, Duker JS, Baumal CR. An Outbreak of Endogenous Fungal Endophthalmitis Among Intravenous Drug Abusers in New England. JAMA Ophthalmol. 2017; 135:534-540. [PubMed: 28426852]

15. Modjtahedi BS, Finn AV, Papakostas TD, Durand M, Husain D, Eliott D. Intravenous Drug UseAssociated Endophthalmitis. Ophthalmology Retina. 2017; 1:192-199.

16. Grzybowski A, Schwartz SG, Relhan N, Flynn HW Jr. Correspondence. Retina. 2017; 37:e106e107. [PubMed: 28820849]

17. Gregori NZ, Flynn HW Jr, Schwartz SG, et al. Current Infectious Endophthalmitis Rates After Intravitreal Injections of Anti-Vascular Endothelial Growth Factor Agents and Outcomes of Treatment. Ophthalmic Surg Lasers Imaging Retina. 2015; 46:643-648. [PubMed: 26114845]

18. Moshfeghi AA, Rosenfeld PJ, Flynn HW Jr, et al. Endophthalmitis after intravitreal vascular [corrected] endothelial growth factor antagonists: a six-year experience at a university referral center. Retina. 2011; 31:662-668. [PubMed: 21836400]

19. Yannuzzi NA, Gregori NZ, Rosenfeld PJ, et al. Endophthalmitis associated with intravitreal injections of anti-vascular endothelial growth factor agents at a tertiary referral center (in-house and referred cases). (In Press - OSLI-Retina). 
20. Avery RL, Bakri SJ, Blumenkranz MS, et al. Intravitreal injection technique and monitoring: updated guidelines of an expert panel. Retina. 2014; 34(Suppl 12):S1-s18. [PubMed: 25489719]

21. Givner I. Neisseria catarrhalis endophthalmitis; report of a case with complete recovery. Am J Ophthalmol. 1949; 32:699. [PubMed: 18121100]

22. Cao H, Zhang L, Li L, Lo S. Risk factors for acute endophthalmitis following cataract surgery: a systematic review and meta-analysis. PLoS One. 2013; 8:e71731. [PubMed: 23990980]

23. Results of the Endophthalmitis Vitrectomy Study. Arch Ophthalmol. 1995; 113:1479. [PubMed: 7487614]

24. Bui DK, Carvounis PE. Evidence for and against intravitreous corticosteroids in addition to intravitreous antibiotics for acute endophthalmitis. Int Ophthalmol Clin. 2014; 54:215-224. [PubMed: 24613894]

25. Yannuzzi NA, Si N, Relhan N, et al. Endophthalmitis After Clear Corneal Cataract Surgery: Outcomes Over Two Decades. Am J Ophthalmol. 2017; 174:155-159. [PubMed: 27889501]

26. Gills JP. Filters and antibiotics in irrigating solution for cataract surgery. J Cataract Refract Surg. $1991 ; 17: 385$.

27. Ciulla TA, Starr MB, Masket S. Bacterial endophthalmitis prophylaxis for cataract surgery: an evidence-based update. Ophthalmology. 2002; 109:13-24. [PubMed: 11772573]

28. Schwartz SG, Flynn HW Jr, Grzybowski A, Relhan N, Ferris FL 3rd. Intracameral Antibiotics and Cataract Surgery: Endophthalmitis Rates, Costs, and Stewardship. Ophthalmology. 2016; 123:1411-1413. [PubMed: 27342325]

29. Stringham JD, Relhan N, Miller D, Flynn HW Jr. Trends in Fluoroquinolone Nonsusceptibility Among Coagulase-Negative Staphylococcus Isolates Causing Endophthalmitis, 1995-2016. JAMA Ophthalmol. 2017; 135:814-815. [PubMed: 28617914]

30. Chang DF, Braga-Mele R, Henderson BA, Mamalis N, Vasavada A. Antibiotic prophylaxis of postoperative endophthalmitis after cataract surgery: Results of the 2014 ASCRS member survey. J Cataract Refract Surg. 2015; 41:1300-1305. [PubMed: 26189384]

31. Coleman AL. How Big Data Informs Us About Cataract Surgery: The LXXII Edward Jackson Memorial Lecture. Am J Ophthalmol. 2015; 160:1091-1103. e3. [PubMed: 26432566]

32. Meisler DM, Palestine AG, Vastine DW, et al. Chronic Propionibacterium endophthalmitis after extracapsular cataract extraction and intraocular lens implantation. Am J Ophthalmol. 1986; 102:733-739. [PubMed: 3491543]

33. Shirodkar AR, Pathengay A, Flynn HW Jr, et al. Delayed- versus acute-onset endophthalmitis after cataract surgery. Am J Ophthalmol. 2012; 153:391-398. e2. [PubMed: 22030353]

34. Vaziri K, Kishor K, Schwartz SG, et al. Incidence of bleb-associated endophthalmitis in the United States. Clin Ophthalmol. 2015; 9:317-322. [PubMed: 25709395]

35. Medina CA, Butler MR, Deobhakta AA, et al. Endophthalmitis Associated With Glaucoma Drainage Implants. Ophthalmic Surg Lasers Imaging Retina. 2016; 47:563-569. [PubMed: 27327286]

36. Song A, Scott IU, Flynn HW Jr, Budenz DL. Delayed-onset bleb-associated endophthalmitis: clinical features and visual acuity outcomes. Ophthalmology. 2002; 109:985-991. [PubMed: 11986108]

37. Banker TP, McClellan AJ, Wilson BD, et al. Culture-Positive Endophthalmitis After Open Globe Injuries With and Without Retained Intraocular Foreign Bodies. Ophthalmic Surg Lasers Imaging Retina. 2017; 48:632-637. [PubMed: 28810038]

38. Colyer MH, Weber ED, Weichel ED, et al. Delayed intraocular foreign body removal without endophthalmitis during Operations Iraqi Freedom and Enduring Freedom. Ophthalmology. 2007; 114:1439-1447. [PubMed: 17331579]

39. Pieramici DJ, Sternberg P Jr, Aaberg TM Sr, et al. A system for classifying mechanical injuries of the eye (globe). The Ocular Trauma Classification Group. Am J Ophthalmol. 1997; 123:820-831. [PubMed: 9535627]

40. Van Boeckel TP, Brower C, Gilbert M, et al. Global trends in antimicrobial use in food animals. Proceedings of the National Academy of Sciences of the United States of America. 2015; 112:5649-5654. [PubMed: 25792457] 
41. Food and Drug Administration. Summary report on antimicrobials sold or distributed for use in food-producing animals; Food and Drug Administration Summary report 2015. 2014. p. 1-58.Available at https://www.fda.gov/downloads/ForIndustry/UserFees/ AnimalDrugUserFeeActADUFA/UCM476258.pdf

42. US Department of Health Services. Antibiotic resistance threats in the United States, 2013. Centers for Disease Control and Prevention; Atlanta, GA: 2013. http://wwwcdcgov/drugresistance/threatreport

43. Marston HD, Dixon DM, Knisely JM, Palmore TN, Fauci AS. Antimicrobial Resistance. JAMA. 2016; 316:1193-1204. [PubMed: 27654605]

44. Relhan N, Albini TA, Pathengay A, Kuriyan AE, Miller D, Flynn HW Jr. Endophthalmitis caused by Gram-positive organisms with reduced vancomycin susceptibility: literature review and options for treatment. Br J Ophthalmol. 2016; 100:446-452. [PubMed: 26701686]

45. Wilson BD, Relhan N, Miller D, Flynn HW Jr. Gram-Negative Bacteria From Patients With Endophthalmitis: Distribution Of Isolates And Antimicrobial Susceptibilities. Retin Cases Brief Rep. 2017

46. Dave VP, Pathengay A, Nishant K, et al. Clinical presentations, risk factors and outcomes of ceftazidime-resistant Gram-negative endophthalmitis. Clin Exp Ophthalmol. 2017; 45:254-260. [PubMed: 27616274]

47. Kunimoto DY, Das T, Sharma S, et al. Microbiologic spectrum and susceptibility of isolates: part I. Postoperative endophthalmitis. Endophthalmitis Research Group. Am J Ophthalmol. 1999; 128:240-242. [PubMed: 10458187]

48. Relhan N, Pathengay A, Schwartz SG, Flynn HW Jr. Emerging Worldwide Antimicrobial Resistance, Antibiotic Stewardship and Alternative Intravitreal Agents for the Treatment of Endophthalmitis. Retina. 2017; 37:811-818. [PubMed: 28338559]

49. Kuklo P, Grzybowski A, Schwartz SG, Flynn HW Jr, Pathengay A. Hot Topics in Perioperative Antibiotics for Cataract Surgery. Current Pharmaceutical Design. 2017; 23:551-557. [PubMed: 27928966]

50. Patel N, Miller D, Relhan N, Flynn HW Jr. Peptide Nucleic Acid-Fluorescence In Situ Hybridization for Detection of Staphylococci From Endophthalmitis Isolates: A Proof-of-Concept Study. Invest Ophthalmol Vis Sci. 2017; 58:4307-4309. [PubMed: 28800650] 


\section{Table 1}

Potential risk factors for developing endophthalmitis after cataract surgery

\begin{tabular}{|c|c|c|}
\hline & Risk Factors & \\
\hline Preoperative & $\begin{array}{l}\bullet \\
\bullet \\
\bullet \\
\cdot \\
\cdot\end{array}$ & $\begin{array}{l}\text { Presence of significant blepharitis or lid abnormalities } \\
\text { Application of } 2 \% \text { xylocaine gel before povidone-iodine } \\
\text { Diabetes mellitus } \\
\text { Advanced age } \\
\text { Immunocompromised status }\end{array}$ \\
\hline Intraoperative & $\begin{array}{l}\cdot \\
\cdot \\
\cdot \\
\cdot \\
\cdot \\
\cdot\end{array}$ & $\begin{array}{l}\text { Poor sterile technique } \\
\text { Posterior capsular rupture } \\
\text { Vitreous loss and wound leak } \\
\text { Use of intracameral miotics/staining dyes and epinephrine } \\
\text { Contamination during mixing of compounded medications }\end{array}$ \\
\hline Postoperative & $\cdot$ & $\begin{array}{l}\text { Postoperative wound leak } \\
\text { IOL type (silicone versus other) }\end{array}$ \\
\hline
\end{tabular}




\section{Table 2}

Comparison of endophthalmitis by category: Then and Now

\begin{tabular}{|c|c|c|}
\hline Endophthalmitis categories & "Then" & "Now" \\
\hline Post-cataract surgery & Large incisions, ICCE, ECCE & Phacoemulsification, Foldable IOLs \\
\hline - $\quad$ Endophthalmitis Prophylaxis & $\begin{array}{ll}\text { - } & \text { No PI on ocular surface } \\
\text { - } & \text { Meticulous sterile technique } \\
\text { - } & \text { Topical antibiotics }\end{array}$ & $\begin{array}{ll}\text { - } & \text { Preparation of ocular surface } \\
\text { with PI } \\
\text { - } \quad \begin{array}{l}\text { Meticulous sterile technique \& } \\
\text { draping of lashes/lid margins }\end{array} \\
\text { - } \quad \begin{array}{l}\text { Controversy over use of } \\
\text { intracameral antibiotics }\end{array}\end{array}$ \\
\hline - $\quad$ Antibiotics & $\begin{array}{l}\text { Few antimicrobial choices but } \\
\text { widespread utilization }\end{array}$ & $\begin{array}{l}\text { Emerging antimicrobial } \\
\text { resistance }\end{array}$ \\
\hline & & $\begin{array}{l}\text { - Antibiotics Stewardship } \\
\text { programs }\end{array}$ \\
\hline Reported Studies & Retrospective case series & $\begin{array}{ll}\text { - } & \text { Multicenter clinical trials } \\
\text { - } & \text { Big data (e.g. IRIS Registry) }\end{array}$ \\
\hline Post-intravitreal injection & Topical antibiotics always & No topical antibiotics \\
\hline Endogenous & $\begin{array}{l}\text { Immunocompromised status was major } \\
\text { factor }\end{array}$ & Opioid crisis is new cause \\
\hline Chronic-onset endophthalmitis & Causes not recognized & $\begin{array}{l}\text { Less virulent bacteria (e.g. Propionibacterium } \\
\text { acnes) }\end{array}$ \\
\hline Post-glaucoma surgery & Thin atrophic blebs & Exposed tubes/devices \\
\hline Post-trauma & Delayed presentation, Pre-vitrectomy & $\begin{array}{l}\text { Early wound closure } \\
\text { Systemic and/or Intravitreal antibiotics } \\
\text { Frequent pars plana vitrectomy }\end{array}$ \\
\hline
\end{tabular}

ICCE - Intracapsular cataract extraction, ECCE - Extracapsular cataract extraction, IOL - intraocular lens, PI - povidone-iodine, IRIS - Intelligent Research In-Sight 